\title{
Molecular Physiology of the Neural Circuit for Calcineurin- Dependent Associative Learning in Caenorhabditis elegans
}

\author{
Atsushi Kuhara and Ikue Mori \\ Division of Biological Science, Graduate School of Science and Institute for Advanced Research, Nagoya University, Nagoya 464-8602, Japan
}

How learning and memory is controlled at the neural circuit level is a fundamental question in neuroscience. However, molecular and cellular dissection of the neural circuits underlying learning and memory is extremely complicated in higher animals. Here, we report a simple neural circuit for learning behavior in Caenorhabditis elegans, where the calcium-activated phosphatase, calcineurin, acts as an essential modulator. The calcineurin mutant tax-6 showed defective feeding state-dependent learning behavior for temperature and salt. Surprisingly, defective associative learning between temperature and feeding state was caused by malfunctions of two pairs of directly

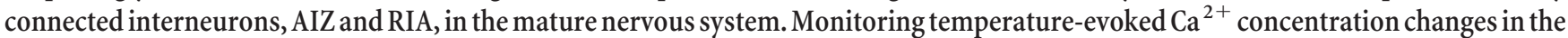
AIZ-RIA neural pathway revealed that starvation, a conditioning factor, downregulated AIZ activity through calcineurin during associative learning between temperature and feeding state. Our results demonstrate the molecular and physiological mechanisms of a simple neural circuit for calcineurin-mediated associative learning behavior.

Key words: C. elegans; thermotaxis; learning and memory; associative learning; calcineurin; neural circuit; calcium imaging

\section{Introduction}

Learning behavior is a highly complex process with intricate neural circuit mechanisms. The modulation of neural signaling through phosphorylation is essential for learning behavior. Protein phosphatases intervene in virtually all steps of neural modulation, and calcineurin, the sole calcium-activated phosphatase, is a key modulator for learning and memory (Mansuy, 2003). However, how the calcineurin-mediated signaling pathway regulates the molecular mechanism and the neural circuit underlying learning behavior remains to be fully elucidated.

The nematode Caenorhabditis elegans is well suited to study the cellular basis of learning behavior because all 302 neurons of its nervous system have been identified, with all known neural connections mapped (White et al., 1986). C. elegans is also suitable for analyzing the molecular mechanism of learning behavior because of its easily accessible genetics and stereotyped behavior (Brenner, 1974; Bargmann and Kaplan, 1998; Mori, 1999).

\footnotetext{
Received Feb. 3, 2006; revised July 26, 2006; accepted July 27, 2006.

This work was supported by research grants from the Japan Society for the Promotion of Science (A.K.) the Ministry of Education, Culture, Sports, Science and Technology of Japan (A.K., I.M.); and the Human Frontier Science Program Organization (I.M.). I.M. is a Scholar of the Institute for Advanced Research of Nagoya University. We thank H. H. B. Cheung, N. Tremain, and M. de Bono for providing tax-6(db60), T. Ishihara for hen-1(tm501), 0. Hobert for the AlY promoter, N. Hisamoto for hsp 16-2 DNA and snb-1::GFP, M. Okumura for several promoters, Y. Tanizawa for the glr-3 short promoter and glr-3p:::snb-1 GFP, J. McGhee for ges-1 promoter, Nippon Avionics (Tokyo, Japan) for the TVS-610 thermal video system, K. D. Kimura for technical advice on calcium imaging, A. Mohri and other members of the Mori laboratory for technical advice and sharing their results before publication, the C. elegans Sequence Consortium for updating the C. elegans genome information, Y. lino, H. Sasakura, E. Kodama, N. Nishio, Y. Okochi, C. I. Bargmann and anonymous reviewers for invaluable comments on this manuscript, and $\mathrm{H}$. Sasakura and other members of the Mori laboratory for stimulating discussions. The Caenorhabditis Genetic Center provided some of the strains used in this study.

Correspondence should be addressed to either Atsushi Kuhara or Ikue Mori, Nagoya University, Graduate School of Science, Molecular Biology, Furo-cho, Chikusa-ku, Nagoya 464-8602, Japan. E-mail: atsushi_kuhara@cc.nagoyau.ac.jp or m46920a@nucc.cc.nagoya-u.ac.jp.

DOI:10.1523/JNEUROSCI.0517-06.2006
}

Copyright $\odot 2006$ Society for Neuroscience $\quad$ 0270-6474/06/269355-10\$15.00/0
C. elegans can respond to various environmental stimuli, such as taste, smell, and temperature, to survive and proliferate (de Bono and Maricq, 2005). Of these, the behavioral response to temperature is observed as thermotaxis behavior, in which $C$. elegans memorizes the environmental temperature and migrates to the cultivation temperature when placed on a thermal gradient (Hedgecock and Russell, 1975; Mori and Ohshima, 1995). Thermotaxis behavior is modulated by feeding state (Hedgecock and Russell, 1975; Mohri et al., 2005). After cultivation at a certain temperature with food, C. elegans migrates to that cultivation temperature. In contrast, $C$. elegans avoids the cultivation temperature after cultivation without food. Based on our previous reports, the feeding state-dependent thermotactic plasticity can be defined as associative learning between temperature and feeding state (Mohri et al., 2005). Laser ablation of specific neurons and genetic experiments have revealed a simple neural circuit for thermotaxis, which contains the thermosensory neuron AFD and its downstream interneurons, AIY, AIZ, and RIA (Mori and Ohshima, 1995; de Bono and Maricq, 2005). It has been proposed that the AIY-mediated neural pathway drives thermophilic movement, that the AIZ-mediated neural pathway drives cryophilic movement, and that the RIA interneuron integrates signals from both of the upstream interneurons AIY and AIZ (Mori and Ohshima, 1995).

In this study, we investigated a neural circuit for associative learning between temperature and feeding state in C. elegans, where calcineurin, encoded by the gene tax-6, modulates neural and behavioral plasticity. We found that a tax -6 mutant showed abnormal associative learning between temperature and feeding state, which was caused by the malfunction of AIZ and RIA interneurons critical for the thermotaxis neural circuit. Physiological analysis using a genetically encodable calcium sensor, cameleon, revealed that thermal responses of AIZ interneurons in 
wild type were downregulated under the starved state. In contrast, AIZ activity in the starved tax- 6 mutant was as active as AIZ in the fed tax- 6 mutant. These results suggest that the neuronal activity of AIZ interneurons is negatively regulated by a starvation signal through calcineurin (TAX-6). Our results allow us to demonstrate a simple neural circuit for calcineurin-mediated associative learning in living animals. We suggest that the molecular and physiological analysis of this neural circuit should shed light on understanding of the fundamental neuronal mechanisms of learning and memory conserved from C. elegans to human.

\section{Materials and Methods}

Strains. The techniques used for culturing and handling C. elegans were essentially as described by Brenner (1974). We used IK656 tax-6(db60) and tax-6(db60); njEx342[pAK2 plasmid] as a tax-6 loss-of-function and the tax-6(sensory+, inter-) mutant, respectively. We also used another tax-6 loss-of-function mutation tax$6(p 675)$ in the experiments presented in Figure $1, F$ and $H$ (Kuhara et al., 2002). The following strains were also used in this study: wild-type $C$. elegans variety Bristol strain (N2) and JC2154 hen-1(tm501).

Thermotaxis assay. A radial temperature gradient assay was performed using a $9 \mathrm{~cm}$ agar plate and a vial containing frozen acetic acid, as described by Mori and Ohshima (1995) and Mohri et al. (2005) with some modification (see Fig. $1 \mathrm{~A}$ ). The L4 larvae were cultured with food (Escherichia coli strain OP50) at the designated temperature for $8-12 \mathrm{~h}$ under uncrowded conditions (12-24 animals per $6 \mathrm{~cm}$ plate). For food-deprived animals, well fed animals were washed three times with nematode growth buffer $\left(0.3 \% \mathrm{NaCl}, 1 \mathrm{~mm} \mathrm{CaCl}, 1 \mathrm{~mm} \mathrm{MgSO}_{4}\right.$, $25 \mathrm{~mm}$ potassium phosphate, $\mathrm{pH}$ 6.0) and were transferred to conditioning plates (2\% agar, 1 $\mathrm{mM} \mathrm{CaCl}, 1 \mathrm{mM} \mathrm{MgSO}_{4}, 25 \mathrm{~mm}$ potassium phosphate, $\mathrm{pH}$ 6.0). The number of animals placed on conditioning plates was restricted to no $>40$ per $9 \mathrm{~cm}$ plate to ensure cultivation under uncrowded conditions. After transfer to the conditioning plate at 17,20 , or $23^{\circ} \mathrm{C}$ for 3,1 , or $0.5 \mathrm{~h}$, respectively (Mohri et al., 2005), thermotaxis of food-deprived animals was assayed. In this study, we used a $45 \mathrm{ml}$ glass vial (Wheaton) for the radial temperature gradient assay, where animals were allowed to move freely for $50 \mathrm{~min}$ on the assay plate. Thermotaxis of individual animals was evaluated using four phenotypic categories: animals that moved to the cold region (the center of the plate) were classified as "17," animals that moved to the region at $20^{\circ} \mathrm{C}$ were classified as " 20 ," animals that moved to the periphery of the plate were classified as "23," and animals that moved to both cold and warm regions were classified as "17/23." The results for these categories were calculated as the percentages of animals showing each phenotype.

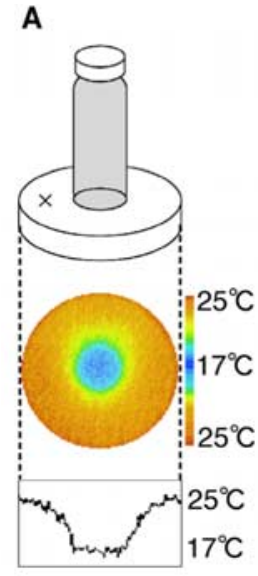

B

$\square 17 \square 17 / 23 \square 20 \square 23$
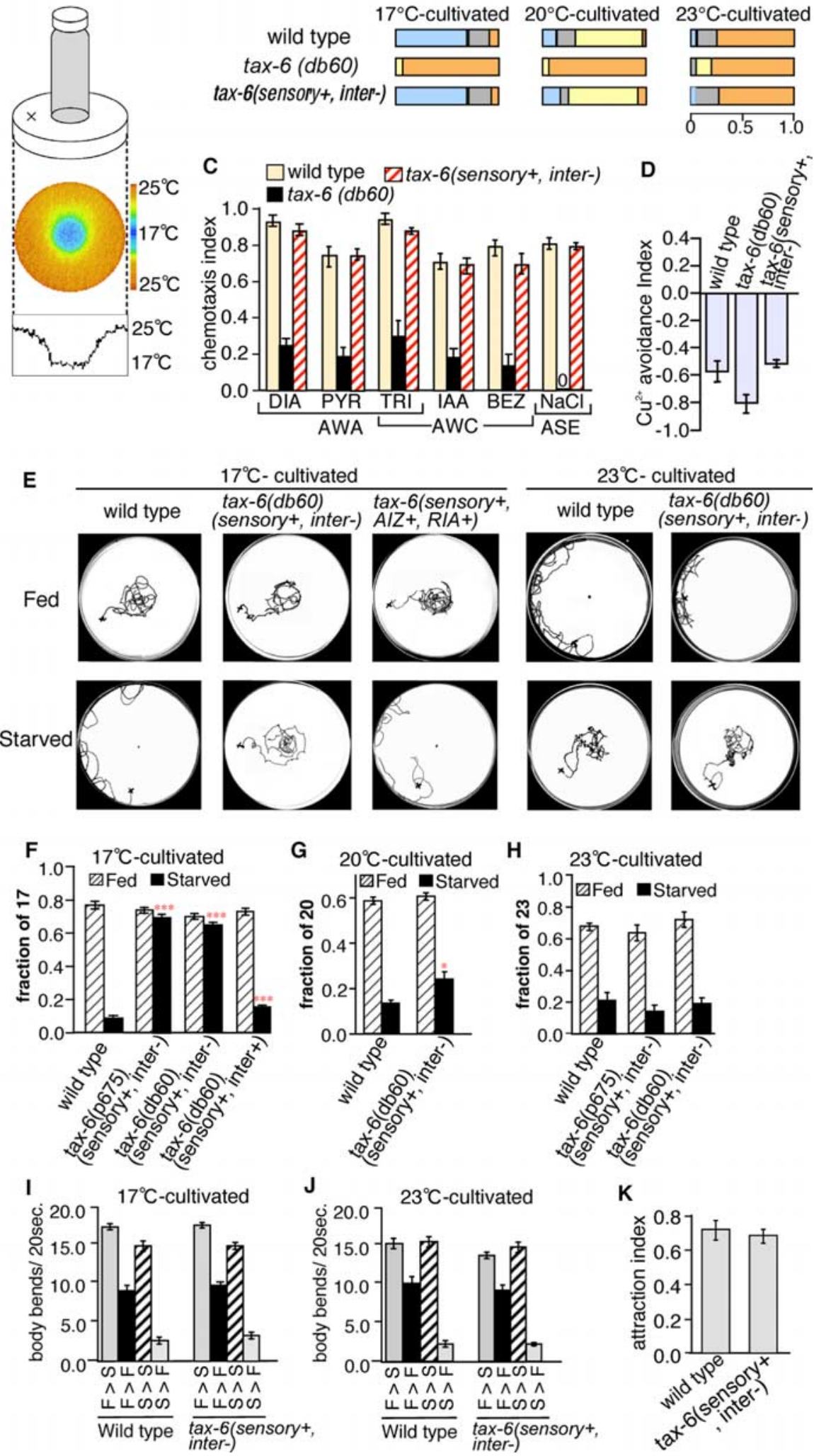

Figure 1. TAX-6 is required for associative learning between temperature and feeding state. $A$, Thermotaxis assay system. The thermograph shows the stable radial temperature gradient from 17 to $25^{\circ} \mathrm{C}$. Single animals were placed on agar at $\sim 22^{\circ} \mathrm{C}$, as indicated by a cross. $\boldsymbol{B}$, The thermotaxis behavior of animals cultivated at 17,20 , and $23^{\circ} \mathrm{C}$. The colored boxes indicate the phenotypic categories as described in Materials and Methods. Each bar represents the average of five independent thermotaxis assays using 20 animals per assay. Three independent transgenic lines were tested for tax-6(sensory + , inter -). For all strains tested, $n=100$. C, Responses to AWA and AWC olfactory neuron-sensed odorants, as well as ASE gustatory neuron-sensed NaCl. DIA, 1:100 diacetyl; PYR, $100 \mathrm{mg} / \mathrm{ml}$ pyrazine; TRI, 1:100 2,4,5-trimethylthiazole; IAA, 1:1000 isoamyl alcohol; BEZ, 1:100 benzaldehyde. Each bar represents the average of nine independent chemotaxis assays using 10 animals per assay. Two 
Locomotory rate assay. The procedure for the locomotory rate assay using a bacterial lawn was essentially according to previous reports with some modifications (Sawin et al., 2000; Mohri et al., 2005). The $6 \mathrm{~cm}$ assay plates $\left(2 \%\right.$ agar, $1 \mathrm{~mm} \mathrm{CaCl}_{2}, 1 \mathrm{~mm} \mathrm{MgSO}_{4}, 25 \mathrm{~mm}$ potassium phosphate, $\mathrm{pH}$ 6.0) were prepared a few hours before the assay by spreading an E. coli (OP50)-enriched solution as described previously (Colbert and Bargmann, 1997). Food-deprived animals grown at 17 or $23^{\circ} \mathrm{C}$ were left on conditioning plates under uncrowded conditions for 3 or $0.5 \mathrm{~h}$, respectively. Two minutes after transfer to the assay plate, the number of body bends was counted for $20 \mathrm{~s}$ for 10 animals of each strain.

Chemotaxis assay. Chemotaxis toward odorants and $\mathrm{NaCl}$ were assayed using the population and the single worm assay systems described previously (Komatsu et al., 1996; Bargmann and Kaplan, 1998). Avoidance of $\mathrm{Cu}^{2+}$ ions was analyzed using the population assay system described by Saeki et al. (2001). Attraction to E. coli (OP50) was assayed as described by Zhang et al. (2005) with some modification, and the OP50 suspension was used as the attractive source. The number of animals was counted after $1 \mathrm{~h}$ and the attraction index was calculated as $A /(A+B)$, where $A$ was the number of the animals on the $E$. coli side of the plate and $B$ was the number of animals on the other side.

Chemotaxis learning assay. Chemotaxis learning for $\mathrm{NaCl}$ was analyzed as described by Saeki et al. (2001) with some modifications (see Fig. 2A). Briefly, animals were washed, placed on a conditioning plate containing $\mathrm{NaCl}$ or a mock conditioning plate not containing $\mathrm{NaCl}$, and incubated at 17,20 , or $23^{\circ} \mathrm{C}$ for $4 \mathrm{~h}$. Animals were then collected, and chemotaxis was assayed on a $6 \mathrm{~cm}$ chemotaxis assay plate with a salt gradient. The number of animals was counted after $20 \mathrm{~min}$, and the index was calculated as $(A-B) /(A+B)$, where $A$ was the number of the animals on the $\mathrm{NaCl}$ side of the plate and $B$ was the number of animals on the other side. Animals that remained at the center were not counted to disregard the effect of differences in motility.

Interaction assay. Integration of two sensory signals was analyzed using the interaction assay described by Ishihara et al. (2002) (see Fig. 2C). Briefly, animals were placed on one side of a $\mathrm{Cu}^{2+}$ barrier on a $9 \mathrm{~cm}$ assay plate, and the attractive odorant diacetyl was spotted on the other side. After $90 \mathrm{~min}$, the number of animals on each side was scored. The index was defined as a percentage of the number of animals on the odorant side to the total number of animals.

Heat shock experiment. Adult animals carrying hsp16-2::tax-6cDNA were placed onto plates $(0 \mathrm{~h})$, allowed to lay eggs for $4 \mathrm{~h}$ at $20^{\circ} \mathrm{C}$, and then removed from the plates. The plates containing eggs were transferred to $15^{\circ} \mathrm{C}$ immediately. The animals were cultivated at $15^{\circ} \mathrm{C}$ for $6 \mathrm{~d}$, and heat shock was performed at $30^{\circ} \mathrm{C}$ for $4 \mathrm{~h}$. The animals were cultivated at $15^{\circ} \mathrm{C}$ for $1-2 \mathrm{~h}$ again and subjected to conditioning.

Molecular biology. In all experiments, we used a modified tax- 6 cDNA and tax-6(H176Q) cDNA containing the $19 \mathrm{bp}$ upstream of the initiation codon ATG, the 15 bp downstream of the stop codon TAG, and the unc-54 3'UTR. The tax-6(H176Q) cDNA has a substitution of the histi- dine $(\mathrm{H})$ at residue 176 , which is critical for phosphatase activity, with glutamine (Q) (Griffith et al., 1995; Kissinger et al., 1995). The tax-6 dominant-negative form (DN) consists of the TAX-6 autoinhibitory domain (K450 to S535) (Perrino et al., 1995; Sagoo et al., 1996; Kuhara et al., 2002). The gain-of-function (gf) forms of tax-6, tax-6gf, and tax$6 g f(H 176 Q)$, lack the TAX-6 autoinhibitory domain (Kuhara et al., 2002). hsp16-2, unc-14p, AIYp, glr-3p, lin-11p, unc-42p, unc-86p, glr-6p, $o d r-2 p$, and $g l r-3 p$ (short) contain $0.45,1.5,0.85,3,1.4,3,3.6,7.4,2.6$, and $2 \mathrm{~kb}$ of each promoter DNA, respectively (Baumeister et al., 1996; Hobert et al., 1997; Ogura et al., 1997; Hobert et al., 1998; Brockie et al., 2001; Chou et al., 2001). The $p A K 2$ plasmid contains $1.1 \mathrm{~kb}$ of the short-type tax-6 promoter and the tax-6 genomic gene (Kuhara et al., 2002).

Germline transformation. Germline transformation was performed by a microinjection method (Mello et al., 1991) using 2-20 ng/ml of the DNA to be tested, along with $50 \mathrm{ng} / \mathrm{ml}$ pKDK66 ges-1p::NLS-GFP DNA and pBluescript SK+ as carrier DNA.

In vivo calcium imaging and data analysis. In vivo calcium imaging was performed essentially according to Kimura et al. (2004) with some modifications. Starved animals were cultivated on a conditioning plate without food at $17^{\circ} \mathrm{C}$ for $3 \mathrm{~h}$, as described previously (Mori and Ohshima, 1995; Mohri et al., 2005). Well fed or starved animals expressing yellow cameleon 2.12 behind the $l i n-11$ promoter or the $g l r-3$ promoter, lin-11p::yc2.12 or glr-3(short)p::yc2.12, respectively, were glued onto a $2 \%$ agar pad on glass, immersed in M9 buffer, and covered by cover glass. The agar pad and M9 buffer were kept at the initial imaging temperature. Sample preparation was completed within $2 \mathrm{~min}$. The sample was then placed onto a MATS-555 thermocontroller (Tokai Hit, Shizuoka-ken, Japan) on the stage of a Nikon (Tokyo, Japan) E600 microscope at the initial imaging temperature for $2 \mathrm{~min}$, and fluorescence was introduced into a W-View optics system (Hamamatsu Photonics, Shizuoka-ken, Japan). Cyan fluorescent protein (CFP; F480) and yellow fluorescent protein (YFP; F535) images were simultaneously captured by a CCD camera HiSCA (Hamamatsu Photonics). Images were taken with a 203 ms exposure time with $4 \times 4$ binning. The temperature on the agar pad was monitored by a thermometer system, DCM-20 (Tokai Hit; Hamamatsu Photonics). For each imaging experiment, fluorescence intensities of F535 and F480 were measured using the AquaCosmos imaging analysis system (Hamamatsu Photonics).

Statistical analysis. All error bars in the figures indicate SEM. The statistical analysis for behavioral experiments was performed by one-way ANOVA for multiple comparisons. A single asterisk $\left({ }^{*}\right)$, double asterisk $\left.{ }^{* *}\right)$, and triple asterisk $\left(^{\star * *}\right)$ in the figures indicate $p<0.05, p<0.01$, and $p<0.001$, respectively. The value of $p$ is probability. Detailed statistical results in each figure are described below. In Figure $1 F, t_{(\mathrm{df})}=2.19$, $p=0.01$ and $t_{(\mathrm{df})}=1.98, p=0.05 ; t_{(\mathrm{df})}=19.07$ and $p<0.001$ for comparison between starved tax-6(db60)(sensory + , inter - ) and starved wild-type; $t_{(\mathrm{df})}=16.15$ and $p<0.001$ for comparison between starved tax-6(p675)(sensory + , inter - ) and starved wild-type; and $t_{(\mathrm{df})}=11.77$ and $p<0.001$ for comparison between starved tax-6(p675)(sensory + , inter - ) and starved tax$6(p 675)($ sensory + , inter +$)$. In Figure $1 G, t_{(\mathrm{df})}=$ $3.36, p=0.01$ and $t_{(\mathrm{df})}=2.31, p=0.05 ; t_{(\mathrm{df})}=$ 3.17 and $p<0.05$ for comparison between starved tax-6(sensory + , inter-) and starved wild-type. In Figure $2 B, t_{(\mathrm{df})}=2.66, p=0.01$ and $t_{(\mathrm{df})}=2.00, p=0.05 ; t_{(\mathrm{df})}=5.78$ and $p<$ 0.001 for comparison between conditioned tax6 (sensory + , inter -$)$ and conditioned wildtype; $t_{(\mathrm{df})}=6.03$ and $p<0.001$ for comparison between conditioned tax-6(sensory + , inter +$)$ and conditioned tax-6(sensory + , inter - ). In Figure $2 D, t_{(\mathrm{df})}=3.25, p=0.01$ and $t_{(\mathrm{df})}=$ 2.26, $p=0.05 ; t_{(\mathrm{df})}=2.11$ and $p>0.05$ for comparison between tax-6(sensory + , inter-) and wild type. In Figure $2 E, t_{(\mathrm{df})}=2.67, p=$ 0.01 and $t_{(\mathrm{df})}=2.00, p=0.05 ; t_{(\mathrm{df})}=5.19$ and $p<0.001$ for comparison between conditioned tax-6(sensory + , inter -$)$ and conditioned tax6(sensory+, hsp::tax-6cDNAwt) after heat of three independent locomotory rate assays using 10 animals per assay. Three independent transgenic lines were tested for tax-6(sensory +, inter -). $\boldsymbol{K}$, Attraction to E. coli (OP50). Each bar represents the average of 10 independent attraction assay using 10 animals per assay. independent transgenic lines were tested for tax-6(sensory + , inter - ). For all strains tested, $n=90$. $D$, Avoidance behavior from dent transgenic lines were tested for tax- $6($ sensory + , inter -$)$. For wild-type, $n=834$. For $\operatorname{tax}-6(d b 60), n=875$. For each tax-6(sensory + , inter-) transgenic line, $n=\sim 800$. $\boldsymbol{E}$, Tracks of individual $17^{\circ} \mathrm{C}$ - and $23^{\circ} \mathrm{C}$-cultivated animals on a radia 政 were tested for tax-6(sensory + inter - ) and tax-6(sensory + inter + ) respectively. For wild-type and for each tax- 6 transgenic line, $n=\sim 320$. $n=318$ for wild-type. For each tax- 6 transgenic line, $n=\sim 320$. G, Results of the thermotaxis assay for $20^{\circ} \mathrm{C}$-cultivated animals. Each bar represents the average of at least four independent thermotaxis assays using 20 animals per assay. For wild-type, $n=80$. For tax-6(sensory + , inter +$), n=78$. $\boldsymbol{H}$, Results of the thermotaxis assay for $23^{\circ} \mathrm{C}$-cultivated independent transgenic lines were tested for tax-6(sensory + , inter - ) and tax-6(sensory + , inter + ), respectively. For genotype, $n \geq 120$. I, J, Modulation of the locomotory rate. Well fed animals (F) were transferred to assay plates without food (gray bars; $F>S$ ) or with food (black bars; $F>F$ ) and starved animals (S) were transferred to assay plates without food (hatched (gray bars, $F>S$ ) or with food (blackbars, $F>F$ ) and starved animals $(S$ ) were transferred to assay plates without food (hatched 
shock at the adult stage. In Figure $3 B, t_{(\mathrm{df})}=2.60, p=0.01$ and $t_{(\mathrm{df})}=$ 1.97, $p=0.05 ; t_{(\mathrm{df})}=4.19$ and $p<0.01, t_{(\mathrm{df})}=4.64$ and $p<0.01$, $t_{(\mathrm{df})}=4.97$ and $p<0.01, t_{(\mathrm{df})}=4.67$ and $p<0.01, t_{(\mathrm{df})}=3.24$ and $p<$ 0.01 , and $t_{(\mathrm{df})}=10.49$ and $p<0.001$ for comparisons of starved tax$6($ sensory + , inter -$)$ versus starved tax-6(sensory + , inter -$)$ expressing tax-6cDNAwt under the promoters $g l r-3 p, g l r-6 p$, lin-11p, unc-86p, odr$2 p$, and $g l r-3 p+l i n-11 p$, respectively. In Figure $3 D, t_{(\mathrm{df})}=2.60, p=0.01$ and $t_{(\mathrm{df})}=1.97, p=0.05 ; t_{(\mathrm{df})}=5.01$ and $p<$ 0.01 for comparison between starved tax-6(sensory + , inter - ) expressing tax-6cDNAwt under driving $g l r-3 p+l i n-11 p$ and starved wild type. In Figure $3 E, \quad t_{(\mathrm{df})}=2.64, \quad p=0.01$ and $t_{(\mathrm{df})}=1.99, p=0.05 ; t_{(\mathrm{df})}=2.69$ and $p<0.01$ for comparison between wild type expressing tax-6cDNAwt and wild type; $t_{(\mathrm{df})}=5.66$ and $p<$ 0.001 for comparison between wild type expressing tax-6cDNAgf and wild type. In Figure $3 F, t_{(\mathrm{df})}=2.64, p=0.01$ and $t_{(\mathrm{df})}=1.99, p=0.05$; $t_{(\mathrm{df})}=2.48$ and $p<0.05$ for comparison between wild type expressing tax-6cDNAwt and wild type; $t_{(\mathrm{df})}=6.17$ and $p<0.001$ for comparison between wild type expressing tax-6cDNAgf and wild type.

\section{Results}

\section{TAX-6/calcineurin is essential for associative learning between temperature and feeding state}

Calcineurin, the only known $\mathrm{Ca}^{2+}$-activated protein phosphatase in the mammalian brain, is a critical molecule for neural plasticity and learning behavior (Klee et al., 1979; Mansuy et al., 1998; Malleret et al., 2001; Mansuy, 2003). We therefore explored the role of calcineurin in learning behavior at the neural circuit level using $C$. elegans. The sole calcineurin catalytic subunit encoded by the gene tax- 6 is expressed in nearly all C. elegans neurons, including interneurons (Kuhara et al., 2002), which should be the essential site for learning processes (Mori and Ohshima, 1995). Because the tax-6(db60) calcineurin loss-of-function mutants show abnormal sensory behavior that is caused by defective TAX-6/calcineurin function in sensory neurons (Kuhara et al., 2002), we first attempted to rescue the abnormal sensation of the tax-6 loss-of-function mutants by expressing wild-type tax-6 gene in sensory neurons. To elucidate whether the sensory neuronal function of the tax-6(sensory + , inter-) mutants was normal, we assayed their sensory behaviors. After cultivation at 17, 20 , and $23^{\circ} \mathrm{C}$ with food, wild-type animals migrated to each cultivation temperature on a radial temperature gradient (Fig. $1 A, B, E)$, whereas tax-6(db60) mutants showed thermophilic abnormalities caused by hyperactivation of AFD thermosensory neurons (Figs. 1B, 3A) (Kuhara et al., 2002). Well fed tax$6($ sensory + , inter -$)$ mutants migrated to each cultivation temperature, implying normal functioning of the thermosensory neurons. The responses of tax-6(sensory+, inter-) mutants to AWA and AWC olfactory neuron-sensed odorants, ASE gustatory neuron-sensed $\mathrm{NaCl}$, and $\mathrm{ASH}$ and $\mathrm{ADL}$ neuron-sensed $\mathrm{Cu}^{2+}$ ions were normal, as in wild-type animals (Fig. 1C,D) (Bargmann and Horvitz, 1991; Bargmann et al., 1993; Ishihara et al., 2002). These results indicate that the sensory neuronal function is normal in tax-6(sensory + , inter-) mutants, although interneurons remain defective.

We used an associative-learning paradigm with temperature and feeding state to test whether TAX-6 calcineurin is required for learning behavior (Fig. $1 \mathrm{E}-H$ ) (Ishihara et al., 2002; Mohri et al., 2005). Most of the well fed wild-type animals cultivated at 17, 20 , or $23^{\circ} \mathrm{C}$ migrated to their respective cultivation temperature on a radial temperature gradient, whereas they avoided the cultivation temperature after cultivation without food (Fig. $1 E-H$ ). In contrast, the interneuron defective calcineurin mutant tax6 (sensory + , inter - ) failed to avoid the cultivation temperature after cultivation without food at $17^{\circ} \mathrm{C}$ (Fig. $\left.1 E, F\right)$. The $p 675 \mathrm{mu}-$ tation is another tax-6 loss-of-function mutation, which led to almost the same abnormality as the $d b 60$ mutation (Fig. $1 F)(\mathrm{Ku}-$ hara et al., 2002). The abnormal associative learning between temperature and feeding state of the tax-6(sensory + , inter - ) was fully rescued in tax-6(sensory + , inter + ) animals expressing tax-6 cDNA in both sensory and interneurons of tax-6(db60) mutants using the unc-14 pan-neuronal promoter (Ogura et al., 1997) (Figs. $1 F, 3 C$ ). These results suggest that the abnormal associative learning between temperature and feeding state in tax-6 mutants is caused by defective TAX-6 calcineurin function in the interneurons. After starvation at 20 or $23^{\circ} \mathrm{C}$, most of the tax6 (sensory + , inter -$)$ mutant animals avoided the conditioning temperature, although $20^{\circ} \mathrm{C}$-cultivated tax-6(sensory + , inter-) mutants were slightly abnormal (Fig. $1 G, H$ ). These results indicate that there are temperature-dependent mechanisms in associative learning between temperature and feeding state, as reported previously (Mohri et al., 2005).

\section{tax-6(sensory + , inter-) mutant animals recognize the feeding state}

Previous reports have proposed a conceptual model for associative learning between temperature and feeding state that consists of several steps, including recognition of temperature and feeding state and association of the received information (Mori and Ohshima, 1995; Mohri et al., 2005). To assess whether tax$6($ sensory + , inter -$)$ mutants can recognize the feeding state, an important step in the conceptual thermotaxis model, we tested feeding-state modulation of locomotory activity (Fig. 1 $I, J$ ) (Sawin et al., 2000; Mohri et al., 2005). Well fed wild-type animals moved more slowly on plates with food than on those without and when starved animals were transferred onto plates with food, they began moving extremely slowly. tax-6(sensory + , inter-) mutants exhibited the same responses as wild-type animals in locomotory rate assays at 17 and $23^{\circ} \mathrm{C}$ (Fig. $\left.1 I, J\right)$. Furthermore, tax-6(sensory + , inter-) mutant animals showed normal attraction to food (E. coli) (Fig. $1 \mathrm{~K}$ ) and showed normal responses to volatile and water-soluble chemicals that could be important cues for food recognition (Fig. 1C). These results imply that tax6 (sensory + , inter - ) mutants recognize a feeding state but are defective in their ability to modulate thermotaxis according to cultivation temperature or feeding.

\section{TAX-6 is required for chemotaxis learning, but not required for integration of sensory inputs}

To elucidate whether TAX-6 calcineurin is involved in other learning behaviors, we tested salt chemotaxis learning (Fig. $2 A, B$ ) (Saeki et al., 2001; Ishihara et al., 2002). After cultivation without $\mathrm{NaCl}$ under starvation conditions, wild-type animals migrated toward the highest concentration of $\mathrm{NaCl}$ on an assay plate containing $\mathrm{NaCl}$ gradient (Fig. $2 \mathrm{~B}$, mock-conditioned). In contrast, wild-type animals avoided $\mathrm{NaCl}$ after cultivation with $\mathrm{NaCl}$ under starvation conditions (Fig. $2 \mathrm{~B}$, conditioned). hen1(tm501), a loss-of-function mutation of a secretory protein with a low-density lipoprotein receptor motif, exhibited abnormal salt chemotaxis learning as reported previously (Ishihara et al., 2002). We found that tax-6(sensory + , inter-) mutants also showed abnormal salt chemotaxis learning and that this abnormality was rescued in tax-6(sensory + , inter + ) animals expressing tax-6 cDNA in both sensory neurons and interneurons. These results imply that TAX-6 calcineurin is also important for salt chemotaxis learning behavior in interneurons.

Because tax-6(sensory + , inter-) mutants showed abnormal learning behavior in two types of learning paradigms, we also 
investigated whether TAX-6 calcineurin is involved in the integration of sensory signals, using an interaction assay system that enabled us to evaluate the integration of two sensory signals at the behavioral level (Fig. $2 C, D$ ) (Ishihara et al., 2002). Wild-type animals were repelled from $\mathrm{Cu}^{2+}$ ions and were attracted to the volatile odorant diacetyl (Fig. $1 C, D$ ). When these two chemosensory stimuli were presented simultaneously, however, chemotaxis toward diacetyl was suppressed because of the presence of the $\mathrm{Cu}^{2+}$ barrier, and as a result, only $26 \%$ of wild-type animals migrated to diacetyl (Fig. 2D). hen-1(tm501) mutants are defective in the interaction of the two chemosensory signals (Ishihara et al., 2002), but tax-6(sensory+, inter-) mutants were normal in the interaction assay (Fig. 2D), suggesting that TAX- 6 calcineurin is not required for integration of two different chemosensory signals.

\section{TAX -6 calcineurin acts in the mature nervous system}

To elucidate learning behavior, we performed behavioral assays in adult-stage animals when all the neuronal connections had already been made and were likely to be fully functional. To confirm whether TAX-6 calcineurin is required in the mature neural circuit, TAX-6 was expressed at either the larval (L1) or adult stage in tax-6(sensory + , inter-) mutants using a heat shock promoter (hsp), and salt chemotaxis learning was analyzed at the adult stage (Fig. 2E) (Ishihara et al., 2002). TAX-6 expression in tax$6($ sensory + , inter - ) larvae did not influence salt chemotaxis learning at the adult stage [Fig. 2E middle, tax-6(sensory+, hsp::tax-6cDNAwt)]. However, TAX-6 expression in tax-6(sensory + , inter-) adult animals did rescue the abnormal salt chemotaxis learning [Fig. 2E right, tax6(sensory+, hsp::tax-6cDNAwt)]. A TAX-6 phosphatase-negative form, TAX-6(H176Q), did not rescue salt chemotaxis learning when expressed at either the larval or adult stage [Fig. 2E, tax-6(sensory+, hsp::tax-6(H176Q)]. These results suggest that TAX- 6 calcineurin is not necessary for neural development but that it regulates neural function in the mature nervous system.

\section{Defective associative learning between temperature and feeding state of the tax-6(sensory+, inter-) mutant is caused by abnormal TAX-6 function in AIZ and RIA interneurons} tax-6(sensory + , inter -$)$ mutants exhibited defective associative learning between temperature and feeding state, which was caused by abnormal TAX- 6 calcineurin function in the interneurons (Fig. $1 F$ ). TAX-6 expression is observed in almost all inter-

A

C

E

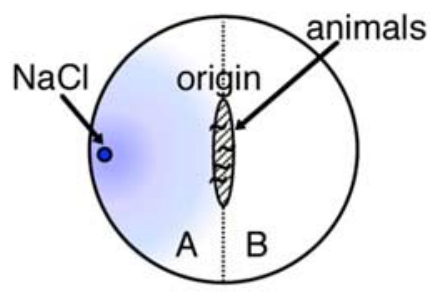

Chemotaxis index $=\frac{A-B}{A+B}$

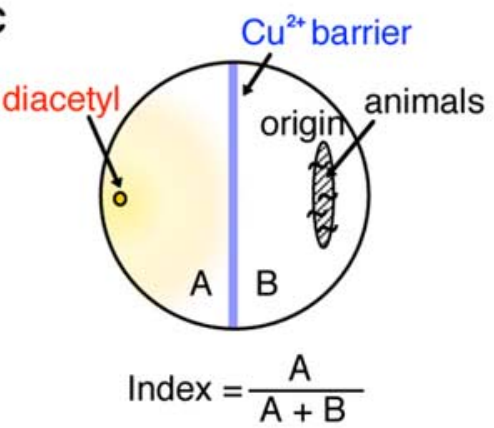
$\square$ wild type
tax-6(sensory+, inter-)
tax-6(sensory+, hsp::tax-6cDNAwt)
tax-6(sensory+, hsp::tax-6(H176Q))

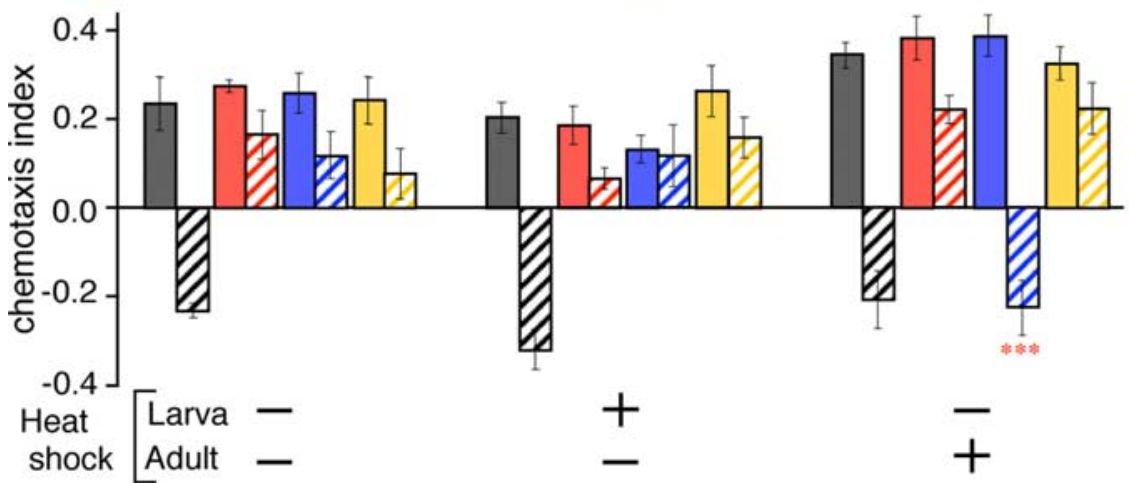

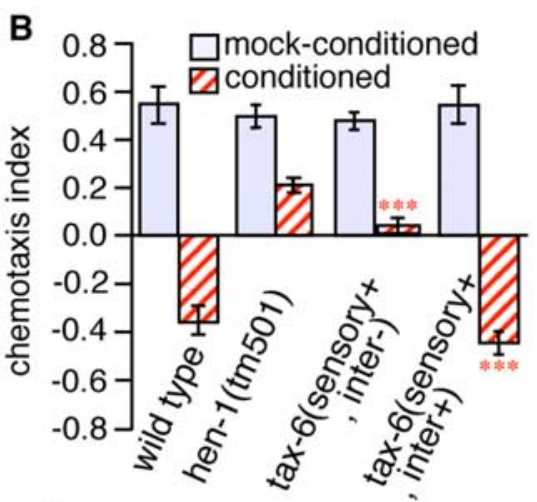

D

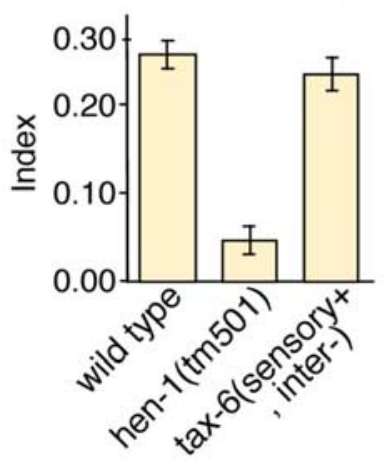

Conditioned

Qwild type Qtax-6(sensory+, inter-) Dtax-6(sensory+, hsp::tax-6(H176Q) $\triangle$ tax-6(sensory+, hsp::tax-6cDNAwt)

Figure 2. TAX-6 calcineurin regulates neural function in the mature nervous system for feeding state-dependent learning behavior. A, Schematic diagram for the assay for salt gustatory plasticity for NaCl (Saeki et al., 2001). B, Chemotaxis toward NaCl of animals of each genotype conditioned without food and with $\mathrm{NaCl}$ or mock conditioned without food and without $\mathrm{NaCl}$. Each bar represents the average of at least four independent chemotactic plasticity assays using $\sim 150$ animals per assay. Three and two independent transgenic lines were tested for tax-6(sensory + , inter - ) and tax-6(sensory + , inter + ), respectively. For wild-type, $n=649$. For hen-1(tm501), $n=621$. For each tax-6 transgenic line, $n=\sim 670$. C, Schematic diagram for the interaction assay (Ishihara et al., 2002). D, Results of the interaction assay. Each bar represents the average of three independent interaction assays using $\sim 60$ animals per assay. Three independent transgenic lines were tested for tax-6(sensory + , inter-). For wild-type, $n=182$. For hen-1(tm501), $n=191$. For each tax-6(sensory + , inter-) transgenic line, $n=\sim 180$. E, tax-6(db60) animals carrying $h s p:: t a x-6$ were heat shocked at various developmental stages and analyzed by the chemotactic plasticity assay. Each bar represents the average of at least three independent chemotactic plasticity assays using $\sim 50$ animals per assay. Four and three independent transgenic lines were tested for tax-6(sensory + , hsp::tax-6cDNAwt) and tax6(sensory+, hsp::tax-6(H176Q), respectively. For wild-type and tax-6(sensory+, inter-), $n=\sim 150$. For each tax6(sensory,+ hsp::tax-6cDNAwt) and tax-6(sensory + , hsp::tax-6(H1760) transgenic line, $n=\sim 140$. neurons, including RIA, AIZ, and AIY interneurons that are critical for the thermotaxis neural circuit (Fig. 3A) (Kuhara et al., 2002). The defective associative learning between temperature and feeding state in tax-6(sensory + , inter-) mutants could result 
A

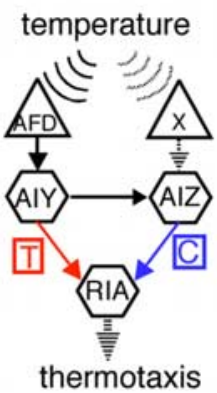

B

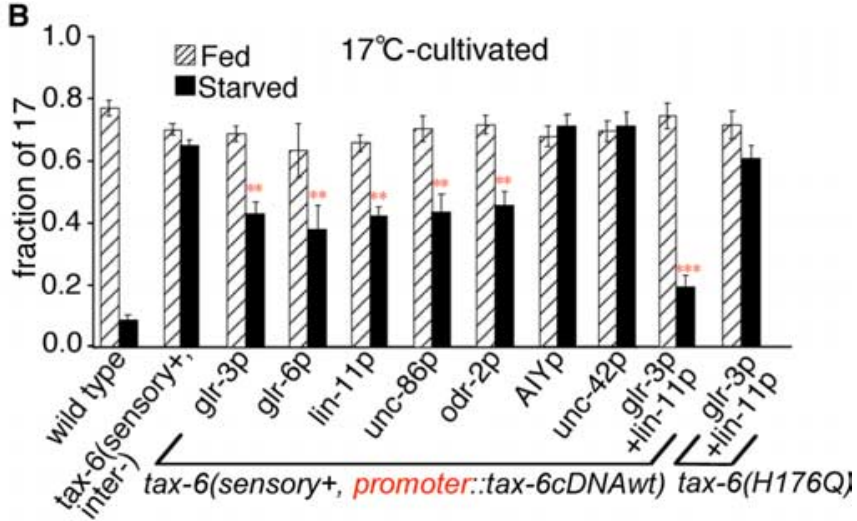

C

\begin{tabular}{|c|c|c|}
\hline $\begin{array}{l}\text { promoter: } \\
\text { tax-6CDNA }\end{array}$ & rescue & expression pattern ( promoter::GFP \\
\hline unc-14p & + & $\begin{array}{l}\text { all neurons } \\
\text { (including sensory and interneurons) }\end{array}$ \\
\hline$g / r-3 p$ & $+1-$ & RIA \\
\hline$g / r-6 p$ & $+\%$ & RIA \\
\hline lin-11p & $+\%$ & ADF, ADL, AIZ, AVG, AVH, AVJ, RIC \\
\hline unc- $86 p$ & $+\%$ & $\begin{array}{l}\text { ADA, AIM, AIZ, ALM, ALN, BDU, FLP, } \\
\text { HSN, IL2, NSM, PLM, URY }\end{array}$ \\
\hline$o d r-2 p$ & $+\%$ & AIB, AIZ, ASG, AVG, IL2, PVP, RIF, RIV, SIAV \\
\hline$A / Y p$ & - & AIY \\
\hline unc-42p & - & $\begin{array}{l}\text { AIN, ASH, AVA, AVD, AVE, AVH, AVJ, } \\
\text { AVK, DD, RIV, RMD, SAA, SIB, SMD }\end{array}$ \\
\hline $\begin{array}{l}\text { glr-3p+ } \\
\text { lin-11p }\end{array}$ & + & RIA, ADF, ADL, AIZ, AVG, AVH, AVJ, RIC \\
\hline
\end{tabular}

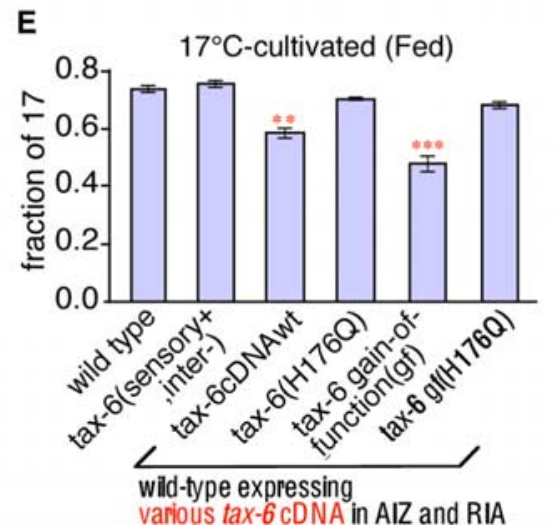

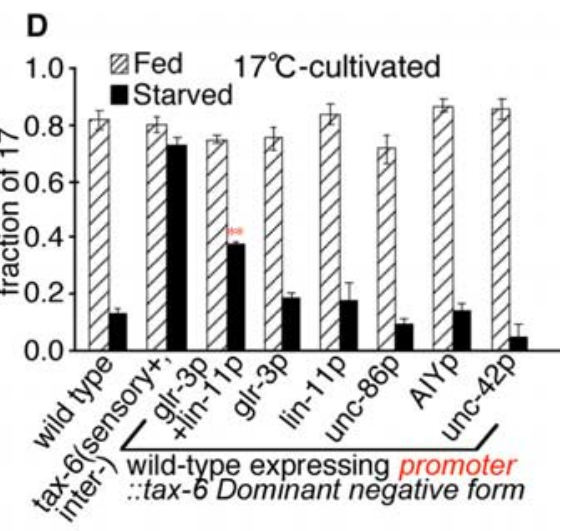

$\mathbf{F}$

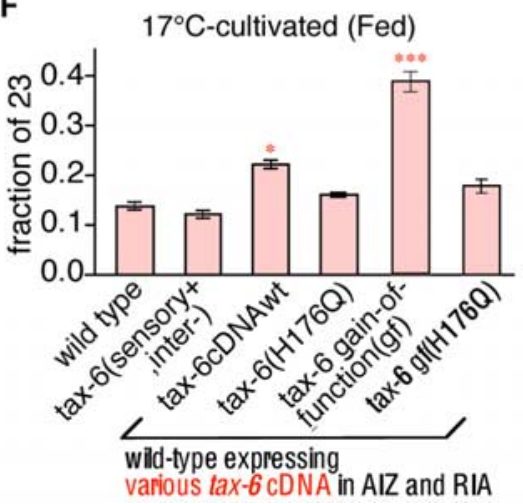

Figure 3. Essential interneurons for TAX-6/calcineurin-mediated thermotactic associative learning. $\boldsymbol{A}$, Schematic diagram of the neural circuit underlying thermotaxis (Mori and Ohshima, 1995). A temperature signal is sensed by the AFD and unidentified $X$ thermosensory neurons; it is then transmitted to AIY and AIZ interneurons, and then finally integrated in the RIA interneuron. The AIY thermophilic ( $T$ ) and AIZ cryophilic $(C)$ arms of the circuit mediate movement to higher (red) and lower (blue) temperatures, respectively. $\boldsymbol{B}$, Rescue experiments of defective temperature-feeding state associative learning in the tax- 6 mutant. Each bar represents the average of at least three independent thermotaxis assays using 20 animals per assay. Two or three independent transgenic lines were tested for tax-6(sensory + ) animals expressing tax-6cDNAwt driven by various promoters. For wild-type and tax-6(sensory + , inter - ), $n=120$. For each tax-6(sensory + , promoter::tax-6cDNAwt) transgenic line, $n \geq 100$. C, Summary for rescue experiments of defective associative learning between temperature and feeding state of tax- 6 mutant. $D$, The effect of the TAX-6 dominant-negative form on thermotaxis. Each bar represents the average of at least three independent thermotaxis assays using 20 animals per assay. Three independent transgenic lines were tested for tax-6(sensory + ) animals expressing the tax- 6 dominant-negative form driven by various promoters. $n \geq 120$ animals for each genotype. $\boldsymbol{E}, \boldsymbol{F}$, Results of the thermotaxis assay conducted at $17(\boldsymbol{E})$ or $23^{\circ} \mathrm{C}(\boldsymbol{F})$ on $17^{\circ} \mathrm{C}$-cultivated fed wild-type animals carrying various types of tax-6 CDNA in AIZ and RIA interneurons. $\mathrm{H} 176 \mathrm{Q}$ indicates the TAX-6 phosphatase negative form. Each bar represents the average of at least three independent thermotaxis assays using 20 animals per assay. Three independent transgenic lines were tested wild-type animals expressing various tax-6 cDNAs. $n \geq 80$ animals for each genotype.

from malfunction of these interneurons. To identify its site of action, tax 6 cDNA was expressed in subsets of interneurons in tax-6(sensory+, inter-) mutants (Fig. $3 B, C)$. The associative learning defect in tax-6(sensory + , inter-) mutants was partially rescued by expressing tax- 6 cDNA under the $g l r-3, g l r-6, l i n-11, u n c-86$, and odr-2 promoters, but not under other promoters (Fig. 3B). The $g l r-3$ and $g l r-6$ promoters allowed TAX-6 expression in RIA interneurons (Fig. 3C) (Brockie et al., 2001), whereas the lin-11, unc-86, and odr-2 promoters allowed TAX-6 expression in AIZ interneurons (Baumeister et al., 1996; Hobert et al., 1998; Chou et al., 2001). Expression of tax- 6 cDNA in both RIA and AIZ interneurons using $g l r-3$ and $l i n-11$ promoters almost fully rescued the abnormal associative learning between temperature and feeding state in tax-6(sensory + , inter - ) mutants [Figs. 1E, tax-6(sensory+, AIZ+, $R I A+), 3 B, C]$, although the TAX-6 phosphatase-negative form (Griffith et al., 1995; Kissinger et al., 1995), tax-6(H176Q), did not rescue the learning defect (Fig. 3B). Expressing the TAX-6 dominant-negative form in both AIZ and RIA interneurons of wild-type animals led to abnormal associative learning (Fig. 3D) (Perrino et al., 1995; Sagoo et al., 1996). Taking these data together, we concluded that TAX-6 calcineurin is required for associative learning between temperature and feeding state in two pairs of interneurons, AIZ and RIA, and that TAX-6 phosphatase activity is indispensable for this process.

The AIZ and RIA interneurons of the tax-6(sensory + , inter-) mutant were visualized using the lin-11p::GFP and $g l r-3 p:: G F P$ soluble green fluorescent protein (GFP) markers, respectively, and no morphological defects of the interneurons were observed in tax-6(sensory + , inter-) mutants cultivated under the fed or starved condition (data not shown). The GFP expression levels in AIZ and RIA neurons were also similar between wild-type and tax-6(sensory + , inter-) mutants (data not shown). The localization of a GFP-tagged synaptic protein synaptobrevin, SNB-1::GFP, was normal in the axon of RIA neurons in tax-6(sensory+, inter-) mutant animals (data not shown). We could not observe SNB-1::GFP localization in the axon of AIZ neurons specifically, because no AIZ-specific promoters have yet been developed. These results imply that TAX-6 calcineurin affects neural function but not the development of AIZ and RIA interneurons.

TAX-6 activation led to less activation of cryophilic driving, and more activation of a thermophilic driving

TAX-6 calcineurin is required for associative learning between temperature and feeding state in two pairs of interneurons, AIZ and RIA. AIZ and RIA are essential component interneurons for the thermotaxis neural circuit and the AIZ-RIA neural pathway constitutes criti- 
cal wiring for cryophilic movement, which plays an antagonistic role to the AIY-RIAmediated thermophilic driving pathway (Fig. 3A) (Mori and Ohshima, 1995, 1997; Mori, 1999). Because calcineurin acts as a negative regulator for synaptic plasticity in the mammalian hippocampus (Mansuy et al., 1998; Malleret et al., 2001), we investigated whether TAX-6 calcineurin negatively regulates the thermotactic signaling pathway in the AIZ-RIA pathway by using the gain-offunction form of tax-6 lacking the calcineurin autoinhibitory domain (Kuhara et al., 2002). The cryophilic phenotype of well fed wild-type animals cultivated at $17^{\circ} \mathrm{C}$ decreased with expression of tax- $6 g f$ in both AIZ and RIA interneurons (Fig. 3E), suggesting that activating TAX- 6 calcineurin in AIZ and RIA led to less activation of cryophilic driving. In contrast, the thermophilic phenotype of these transgenic animals increased despite $17^{\circ} \mathrm{C}$ cultivation (Fig. $3 F$ ). These results imply that TAX- 6 activation in AIZ and RIA neurons results in less activation of the cryophilic driving pathway and more activation of the thermophilic driving pathway.

Starvation downregulates AIZ neuronal activity through TAX-6 calcineurin during associative learning between temperature and feeding state

We next investigated how the AIZ-RIA neural pathway is physiologically regulated during associative learning between temperature and feeding state. Because intracellular $\mathrm{Ca}^{2+}$ concentration is known to correlate with neural activity, we monitored temperature stimulus-evoked $\mathrm{Ca}^{2+}$ concentration changes in intact AIZ-RIA interneurons using a genetically encoded calcium indicator, cameleon (Fig. 4) (Miyawaki et al., 1997; Kimura et al., 2004). We found that the $\mathrm{Ca}^{2+}$ concentration in AIZ interneurons of well fed wild-type animals cultivated at $17^{\circ} \mathrm{C}$ increased with warming and decreased with cooling (Fig. $4 A-D, F$ ), but the responses of RIA interneurons were minimal (Fig. $4 E$ ). The minimal responses of RIA interneurons might be related to the sensitivity of the detection limit of the cameleon protein, or to the thermotaxis neural circuit, where the RIA interneurons receives opposing cryophilic and thermophilic driving signals. Other interneurons not directly connected to the major thermotaxis-related neurons did not strongly respond to temperature changes (data not shown). The neuronal activities of AIZ interneurons in starved wild-type animals cultivated at $17^{\circ} \mathrm{C}$ were much less responsive to temperature changes (Fig. 4C,F). However, AIZ activities in starved tax$6($ sensory + , inter -$)$ mutant animals were as active as AIZ interneurons of fed tax-
A

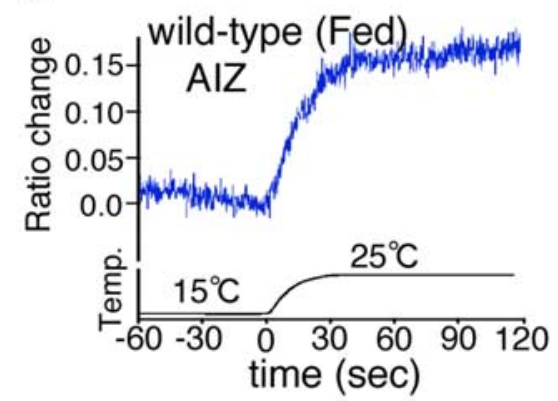

C

\section{wild-type $\left(17^{\circ} \mathrm{C}\right.$-cultivated $)$}
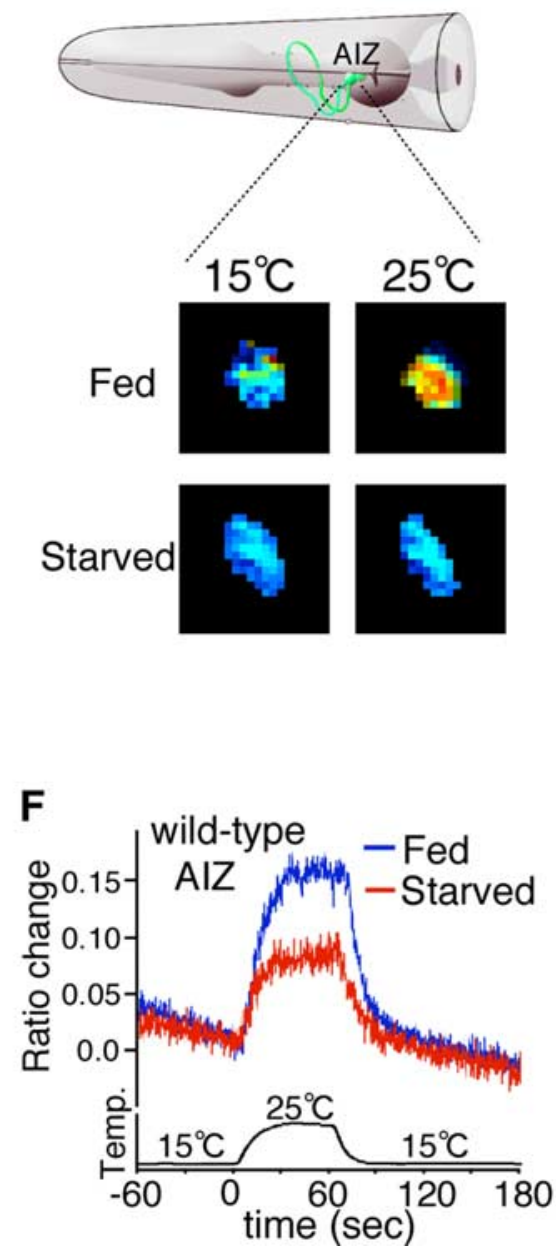

Figure 4. In vivo calcium ratio imaging of the neural circuit for feeding state-dependent thermotactic plasticity. Calcium ratio imaging of AIZ $(\boldsymbol{A}-\boldsymbol{D}, \boldsymbol{F}, \boldsymbol{G})$ and RIA interneurons $(\boldsymbol{E})$ in $17^{\circ} \mathrm{C}$-grown animals cultivated under the fed or starved condition. Each graph represents the average response of AIZ or RIA interneurons to thermal stimuli. Each data were aligned at stimulus onset. Relative increases or decreases in the intracellular calcium concentration were measured as increases or decreases in the YFP/CFP fluorescence ratio of the cameleon protein (ratio change), respectively. Temperature (temperature) is shown as a thin black line at the bottom of the graph. $A$, The AIZ interneuron in wild type responds to warming. The average ratio change from baseline \pm SEM is $0.143 \pm 0.008$; $n=12 . B$, The AIZ interneuron in wild type responds to cooling. The average ratio change from baseline \pm SEM is $-0.155 \pm 0.013$; $n=11$. C, A schematic diagram of an AIZ interneuron (green, top) in the C. elegans head, and corresponding pseudocolor images (bottom) depicting the fluorescence ratio before (left) and during (right) temperaturechanges. Blue and red pixels represent lower and higher fluorescence ratios, respectively. $\boldsymbol{D}$, The AIZ interneurons respond to step-like temperature changes; $n=10$. $\boldsymbol{E}$, Calcium ratio imaging of RIA interneurons in wild-type animals cultivated under the fed or starved condition. The average ratio changes from baseline \pm SEM are $0.04 \pm 0.004$ (fed) and $0.038 \pm 0.007$ (starved). Fed, $n=10$; starved, $n=10$. F, Calcium ratio imaging of AIZ interneurons in wild-type animals cultivated under the fed or starved condition. Fed, $n=20$; starved, $n=21$. The average ratio changes from baseline \pm SEM are $0.145 \pm 0.009$ (fed) and $0.073 \pm 0.010$ (starved). G, Calcium ratio imaging of AlZ interneurons in tax-6(sensory + , inter - ) mutant animals cultivated under the fed or starved condition. The average ratio changes from baseline \pm SEM are $0.122 \pm 0.010$ (fed) and $0.140 \pm 0.013$ (starved). Fed, $n=21 ;$ starved, $n=27$. 
wild-type $\left(17^{\circ} \mathrm{C}\right.$-cultivated $)$
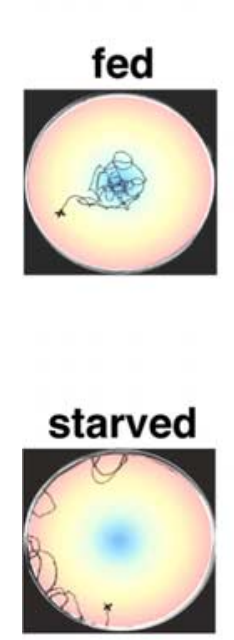
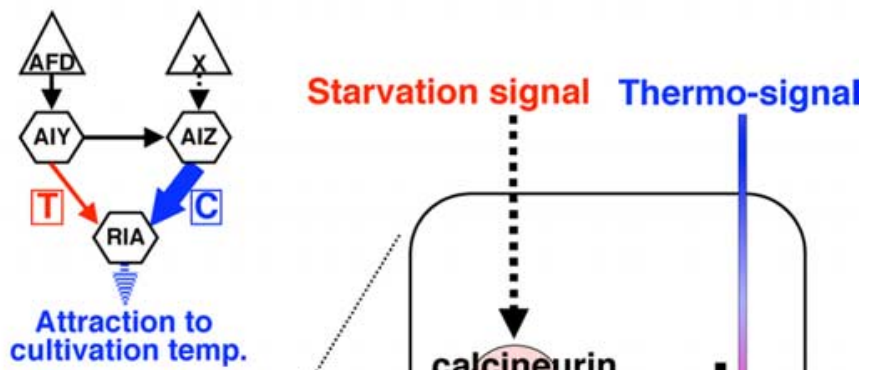

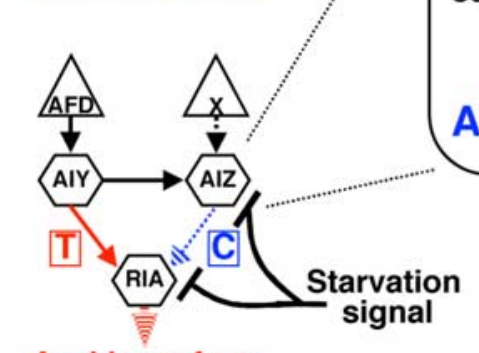

Avoidance from

cultivation temp.

Figure 5. A neural circuit model for associative learning between temperature and feeding state. In fed wild-type animals cultivated at $17^{\circ} \mathrm{C}$, the AIZ-RIA neural pathway is activated, thereby causing fed animals to be attracted to the cultivation temperature (top left and middle). In starved wild-type animals, a starvation signal negatively regulates the AIZ-mediated cryophilic driving pathway through TAX-6 calcineurin (right), leading to a relatively more active state of the thermophilic driving pathways such as the AlY-mediated pathway (bottom middle or bottom left). As a result, starved animals avoid the cultivation temperature (bottom left).

$6($ sensory + , inter-) mutants (Fig. 4G). These results suggest that AIZ neuronal activity is negatively regulated by a starvation signal through TAX-6 calcineurin during associative learning between temperature and feeding state.

\section{Discussion}

\section{Essential neural circuit for calcineurin-mediated} associative learning

In this study, we demonstrated that the calcium-activated phosphatase calcineurin acts as a negative regulator of neural activity in the neural circuit essential for associative learning between temperature and feeding state in vivo. Mutant tax-6(sensory+, inter-) animals defective in TAX-6 calcineurin in interneurons showed abnormal feeding state-dependent learning behaviors. Abnormal associative learning between temperature and feeding state of the tax-6(sensory+, inter-) mutant was rescued by expressing the tax- 6 gene in two pairs of interneurons, AIZ and RIA. The AIZ-RIA neural pathway represents a critical wiring for the thermotaxis neural circuit. Monitoring the change of the temperature-evoked $\mathrm{Ca}^{2+}$ concentration in the AIZ-RIA neural circuit revealed that thermal responses of AIZ interneurons in starved wild-type animals were downregulated through TAX-6 calcineurin. Altogether, we elucidated some of the physiological and molecular mechanisms of the neural circuit important for associative learning between temperature and feeding state, in which TAX-6 calcineurin downregulates neural activity.

Well fed tax-6(sensory + , inter-) mutant animals cultivated at 17,20 , or $23^{\circ} \mathrm{C}$ migrated normally to their respective cultivation temperature (Fig. $1 \mathrm{~B}$ ). These results imply that the memory formation of each cultivation temperature may remain intact in tax-6(sensory + , inter - ) mutants and that the function of TAX-6 calcineurin in interneurons may not be required for the modulation of the thermotactic signaling pathway under fed conditions. model.
In contrast, tax-6(sensory + , inter-) mutant animals showed abnormal associative learning behavior between cultivation temperature and feeding state after cultivation under starvation conditions at low temperature (Fig. 1F), implying that TAX-6 calcineurin is important for associative learning behavior between temperature and starvation after cultivation at low temperature. Additionally, the neuronal activity of AIZ interneurons critical for cryophilic driving was downregulated in starved wild-type animals (Fig. 4F), whereas downregulation of AIZ neuronal activity was not observed in starved tax6(sensory+, inter-) mutants (Fig. 4G). These behavioral and physiological results suggest that TAX-6 calcineurin might be directly or indirectly activated by a starvation signal, leading to starvation-induced negative modulation of the AIZ neuronal activity important for cryophilic driving.

Activating TAX-6 calcineurin in AIZ and RIA neurons of wild-type animals cultivated at $17^{\circ} \mathrm{C}$ decreased cryophilic driving and increased the thermophilic driving despite $17^{\circ} \mathrm{C}$ cultivation (Fig. $3 E, F$ ). These abnormal phenotypes are reminiscent of the phenotypes of AIZ-defective mutants and AIZ-ablated wild-type animals that display thermophilic abnormalities (Mori and Ohshima, 1995; Hobert et al., 1998). In these animals, it is thought that the AIZ-mediated cryophilic driving pathway is the less active state, thereby making the intact thermophilic driving pathways such as the AIY-mediated pathway relatively more active (Mori and Ohshima, 1995; Hobert et al., 1998).

Based on a possible regulatory role for TAX-6 calcineurin in the AIZ-RIA neural circuit, we propose a neural circuit model for associative learning between temperature and feeding state in $17^{\circ} \mathrm{C}$-cultivated animals (Fig. 5). In wild-type animals cultivated at $17^{\circ} \mathrm{C}$ with food, the AIZ-mediated cryophilic driving neural pathway is activated, and as a result the animals are attracted to the cultivation temperature (Fig. 5, top left). In starved wild-type animals, the cryophilic driving pathway is negatively regulated by a starvation signal through TAX-6 calcineurin (Fig. 5, right), which leads to more active thermophilic driving pathways, such as the AIY-mediated pathway, thereby causing starved animals to avoid the cultivation temperature (Fig. 5, bottom left). The role of TAX- 6 calcineurin in the RIA interneuron is probably complicated, because RIA is the integrating interneuron in the thermotaxis neural circuit where cryophilic and thermophilic driving signals should be appropriately processed and integrated. In mammals, calcineurin negatively regulates the function of synaptic components, such as negatively regulating the open probability of a neurotransmitter glutamate receptor (Banke et al., 2000). TAX-6 calcineurin could similarly modulate the neurotransmission at RIA interneuron, such as negatively modulating a postsynaptic molecular component in the synaptic connection between AIZ and RIA. It is also likely that the associative learning is accomplished by more complicated neural circuit mechanisms, although we describe here a plausible simpler neural circuit

Previous analysis demonstrated that the fraction of $17^{\circ} \mathrm{C}$ - 
cultivated wild-type animals that migrated to $17^{\circ} \mathrm{C}$ gradually decreased, and that simultaneously the fraction of animals that migrated to the higher temperature $\left(23^{\circ} \mathrm{C}\right)$ gradually increased in a manner dependent on the length of time under starvation conditions (Mohri et al., 2005). This result suggests that a starvation signal could gradually induce both calcineurin activation and a change in temperature preference. Perhaps these two events occur as an analog response, although the neural circuit model shown in Figure 5 is simplified, showing the system as if it were a digital system, for ease of explanation. Importantly, the neural circuit model for associative learning we propose is biologically testable. We thus suggest that it would serve as a suitable model for computational analysis of neural networks.

\section{Neural mechanism for learning behavior for temperature and $\mathrm{NaCl}$}

tax-6(sensory + , inter-) mutant animals showed defective associative learning between temperature and feeding state after cultivation at low temperature but not at high temperature (Fig. $1 F, H)$. Many mutants showing abnormal associative learning between temperature and feeding state were previously isolated and grouped into three classes (Mohri et al., 2005). The first group exhibits abnormal associative learning after cultivation at both low and high temperatures, the second group exhibits abnormal associative learning at a low temperature, and the last group exhibits abnormal associative learning at a high temperature. The time required for association between cultivation temperature and starvation in wild type also differs depending on cultivation temperature (Mohri et al., 2005). These results indicate that associative learning between temperature and feeding state is probably regulated by both cultivation temperaturedependent and -independent mechanisms. Our results suggest that associative learning between temperature and feeding state at low temperature is controlled through the negative regulation of cryophilic driving. It is possible that associative learning between temperature and feeding state under high temperature conditions is controlled through the negative regulation of thermophilic driving, or alternatively, through the positive regulation of cryophilic driving.

tax-6(sensory + , inter-) mutant animals showed abnormal $\mathrm{NaCl}$ chemotaxis learning that was independent of cultivation temperature (Fig. 2B) (data not shown). Defective chemotaxis learning in tax-6(sensory+, inter-) mutants was caused by an abnormal neural function in the mature neural circuit (Fig. $2 E$ ). Chemotactic plasticity such as gustatory plasticity and olfactory plasticity are mainly controlled in chemosensory neurons (L'Etoile and Bargmann, 2000; Kuhara et al., 2002; L'Etoile et al., 2002; Hukema et al., 2006; Matsuki et al., 2006). However, the function of sensory neurons was normal in tax-6(sensory + , inter-) mutant animals as the defective sensory neurons were rescued, implying that TAX- 6 calcineurin may regulate $\mathrm{NaCl}$ chemotaxis learning in interneurons. A recent study showed that short-term olfactory plasticity is controlled in interneurons (Hirotsu and Iino, 2005). TAX-6 calcineurin likely modulates the chemosignaling pathway in interneurons for the chemotaxis learning neural network, although the interneurons essential for chemotaxis to $\mathrm{NaCl}$ have not been clearly determined. Alternatively, TAX-6 calcineurin possibly acts in a negative feedback system from interneuron to sensory neuron, such as by retrograde endocrine or hormonal signaling, leading to the negative regulation of chemosensory neurons.

Neural circuits consist of a variety of neural cells that probably have individual physiological properties. To understand the prin- ciple neural mechanism of behavioral plasticity, it will be necessary to determine both the neural circuit underlying the specific behavior and the physiological properties of the individual neurons involved. Our present results suggest that a simple neural circuit governs associative learning behavior and demonstrate a physiological property of an essential interneuron in this neural circuit. Future molecular and physiological analysis of this neural circuit and a reconstruction analysis by computational biology may shed light on a fundamental neural circuit mechanism for learning behavior conserved throughout species from C. elegans to human.

\section{References}

Banke TG, Bowie D, Lee H, Huganir RL, Schousboe A, Traynelis SF (2000) Control of GluR1 AMPA receptor function by cAMP-dependent protein kinase. J Neurosci 20:89-102.

Bargmann CI, Horvitz HR (1991) Chemosensory neurons with overlapping functions direct chemotaxis to multiple chemicals in C. elegans. Neuron 7:729-742.

Bargmann CI, Kaplan JM (1998) Signal transduction in the Caenorhabditis elegans nervous system. Annu Rev Neurosci 21:279-308.

Bargmann CI, Hartwieg E, Horvitz HR (1993) Odorant-selective genes and neurons mediate olfaction in C. elegans. Cell 74:515-527.

Baumeister R, Liu Y, Ruvkun G (1996) Lineage-specific regulators couple cell lineage asymmetry to the transcription of the Caenorhabditis elegans POU gene unc-86 during neurogenesis. Genes Dev 10:1395-1410.

Brenner S (1974) The genetics of Caenorhabditis elegans. Genetics 77:71-94.

Brockie PJ, Madsen DM, Zheng Y, Mellem J, Maricq AV (2001) Differential expression of glutamate receptor subunits in the nervous system of Caenorhabditis elegans and their regulation by the homeodomain protein UNC-42. J Neurosci 21:1510-1522.

Chou JH, Bargmann CI, Sengupta P (2001) The Caenorhabditis elegans odr-2 gene encodes a novel Ly-6-related protein required for olfaction. Genetics 157:211-224.

Colbert HA, Bargmann CI (1997) Environmental signals modulate olfactory acuity, discrimination, and memory in Caenorhabditis elegans. Learn Mem 4:179-191.

de Bono M, Maricq AV (2005) Neuronal substrates of complex behaviors in C. elegans. Annu Rev Neurosci 28:451-501.

Griffith JP, Kim JL, Kim EE, Sintchak MD, Thomson JA, Fitzgibbon MJ, Fleming MA, Caron PR, Hsiao K, Navia MA (1995) X-ray structure of calcineurin inhibited by the immunophilin-immunosuppressant FKBP12-FK506 complex. Cell 82:507-522.

Hedgecock EM, Russell RL (1975) Normal and mutant thermotaxis in the nematode Caenorhabditis elegans. Proc Natl Acad Sci USA 72:4061-4065.

Hirotsu T, Iino Y (2005) Neural circuit-dependent odor adaptation in $C$. elegans is regulated by the Ras-MAPK pathway. Genes Cells 10:517-530.

Hobert O, Mori I, Yamashita Y, Honda H, Ohshima Y, Liu Y, Ruvkun G (1997) Regulation of interneuron function in the C. elegans thermoregulatory pathway by the ttx-3 LIM homeobox gene. Neuron 19:345-357.

Hobert O, D'Alberti T, Liu Y, Ruvkun G (1998) Control of neural development and function in a thermoregulatory network by the LIM homeobox gene lin-11. J Neurosci 18:2084-2096.

Hukema RK, Rademakers S, Dekkers MP, Burghoorn J, Jansen G (2006) Antagonistic sensory cues generate gustatory plasticity in Caenorhabditis elegans. EMBO J 25:312-322.

Ishihara T, Iino Y, Mohri A, Mori I, Gengyo-Ando K, Mitani S, Katsura I (2002) HEN-1, a secretory protein with an LDL receptor motif, regulates sensory integration and learning in Caenorhabditis elegans. Cell 109:639-649.

Kimura KD, Miyawaki A, Matsumoto K, Mori I (2004) The C. elegans thermosensory neuron AFD responds to warming. Curr Biol 14:1291-1295.

Kissinger CR, Parge HE, Knighton DR, Lewis CT, Pelletier LA, Tempczyk A, Kalish VJ, Tucker KD, Showalter RE, Moomaw EW, Gastinel LN, Habuka N, Chen X, Maldonado F, Barker JE, Bacquet R, Villafranca JE (1995) Crystal structures of human calcineurin and the human FKBP12-FK506calcineurin complex. Nature 378:641-644.

Klee CB, Crouch TH, Krinks MH (1979) Subunit structure and catalytic properties of bovine brain $\mathrm{Ca}^{2+}$-dependent cyclic nucleotide phosphodiesterase. Biochemistry 18:722-729.

Komatsu H, Mori I, Rhee JS, Akaike N, Ohshima Y (1996) Mutations in a 
cyclic nucleotide-gated channel lead to abnormal thermosensation and chemosensation in C. elegans. Neuron 17:707-718.

Kuhara A, Inada H, Katsura I, Mori I (2002) Negative regulation and gain control of sensory neurons by the C. elegans calcineurin TAX-6. Neuron 33:751-763.

L'Etoile ND, Bargmann CI (2000) Olfaction and odor discrimination are mediated by the C. elegans guanylyl cyclase ODR-1. Neuron 25:575-586.

L'Etoile ND, Coburn CM, Eastham J, Kistler A, Gallegos G, Bargmann CI (2002) The cyclic GMP-dependent protein kinase EGL-4 regulates olfactory adaptation in C. elegans. Neuron 36:1079-1089.

Malleret G, Haditsch U, Genoux D, Jones MW, Bliss TV, Vanhoose AM, Weitlauf C, Kandel ER, Winder DG, Mansuy IM (2001) Inducible and reversible enhancement of learning, memory, and long-term potentiation by genetic inhibition of calcineurin. Cell 104:675-686.

Mansuy IM (2003) Calcineurin in memory and bidirectional plasticity. Biochem Biophys Res Commun 311:1195-1208.

Mansuy IM, Mayford M, Jacob B, Kandel ER, Bach ME (1998) Restricted and regulated overexpression reveals calcineurin as a key component in the transition from short-term to long-term memory. Cell 92:39-49.

Matsuki M, Kunitomo H, Iino Y (2006) Goalpha regulates olfactory adaptation by antagonizing Gqalpha-DAG signaling in Caenorhabditis elegans. Proc Natl Acad Sci USA 103:1112-1117.

Mello CC, Kramer JM, Stinchcomb D, Ambros V (1991) Efficient gene transfer in C. elegans: extrachromosomal maintenance and integration of transforming sequences. EMBO J 10:3959-3970.

Miyawaki A, Llopis J, Heim R, McCaffery JM, Adams JA, Ikura M, Tsien RY (1997) Fluorescent indicators for $\mathrm{Ca}^{2+}$ based on green fluorescent proteins and calmodulin. Nature 388:882-887.

Mohri A, Kodama E, Kimura KD, Koike M, Mizuno T, Mori I (2005) Ge- netic control of temperature preference in the nematode Caenorhabditis elegans. Genetics 169:1437-1450.

Mori I (1999) Genetics of chemotaxis and thermotaxis in the nematode Caenorhabditis elegans. Annu Rev Genet 33:399-422.

Mori I, Ohshima Y (1995) Neural regulation of thermotaxis in Caenorhabditis elegans. Nature 376:344-348.

Mori I, Ohshima Y (1997) Molecular neurogenetics of chemotaxis and thermotaxis in the nematode Caenorhabditis elegans. Bioessays 19:1055-1064.

Ogura K, Shirakawa M, Barnes TM, Hekimi S, Ohshima Y (1997) The UNC-14 protein required for axonal elongation and guidance in Caenorhabditis elegans interacts with the serine/threonine kinase UNC-51. Genes Dev 11:1801-1811.

Perrino BA, Ng LY, Soderling TR (1995) Calcium regulation of calcineurin phosphatase activity by its B subunit and calmodulin. Role of the autoinhibitory domain. J Biol Chem 270:340-346.

Saeki S, Yamamoto M, Iino Y (2001) Plasticity of chemotaxis revealed by paired presentation of a chemoattractant and starvation in the nematode Caenorhabditis elegans. J Exp Biol 204:1757-1764.

Sagoo JK, Fruman DA, Wesselborg S, Walsh CT, Bierer BE (1996) Competitive inhibition of calcineurin phosphatase activity by its autoinhibitory domain. Biochem J 320:879-884.

Sawin ER, Ranganathan R, Horvitz HR (2000) C. elegans locomotory rate is modulated by the environment through a dopaminergic pathway and by experience through a serotonergic pathway. Neuron 26:619-631.

White JG, Southgate E, Thomson JN, Brenner S (1986) The structure of the nervous system of the nematode Caenorhabditis elegans. Philos Trans R Soc Lond B Biol Sci 314:1-340.

Zhang Y, Lu H, Bargmann CI (2005) Pathogenic bacteria induce aversive olfactory learning in Caenorhabditis elegans. Nature 438:179-184. 